\title{
REINVESTMENT BIAS WHEN ANALYZING MUTUALLY EXCLUSIVE ASSETS
}

\author{
by
}

\author{
Robert J. Sweeney \\ Marquette University
}

Capital budgeting decisions generally involve the commitment of resources in the current period to secure positive cash flows over time that generate a rate of return in excess of the cost of the funds invested. The most common techniques used to perform this analysis are the Net Present Value (NPV) and the Internal Rate of Return (IRR) [Bierman and Smidt, 1984; Brigham, 1983].

The NPV calculates the change in present wealth resulting from a decision to accept an investment. If the NPV is positive (negative), the investment is accepted (rejected). The IRR determines the rate of return earned on the investment (the yield-to-maturity). If the IRR exceeds (is less than) the cost of the funds, the investment is accepted (rejected) [Dean, 1954 ].

Conceptually, these two techniques are substitutable; i.e., the resulting decision from a NPV analysis is identical to the decision from an IRR analysis. In practice, however, the NPV and the IRR can, on occassion, produce conflicting decisions. Specifically, when analyzing mutually exclusive assets the Net Present Value can support one asset while the Internal Rate of Return supports the other. The purpose of this paper is twofold; first, to highlight structural deficiencies in the conventional application of the NPV and the IRR, and second, to demonstrate a procedure to correct for these structural errors.

Section one contains a description of the two hypothetical investments available to a firm that are used in the discussion. The section also contains an analysis of the investments using both the NPV and the IRR under the assumption that the investments are independent. The two methods produce identical decisions which confirms the theoretical consistency between the NPV and the IRR. The second section demonstrates how the conflicting signals obtain when analyzing the investments using the NPV and the IRR under the assumption that the investments are mutually exclusive. Section three illustrates the reinvestment bias inherent in each technique. In addition, the third section shows an analysis of the investments incorporating an explicit reinvestment rate. This analysis reestablishes the theoretically consistent decisions between the two approaches. Section four contains the summary.

\section{Independent Investments}

Assume the following information pertains to the two investments currently under consideration. Investment $A$ costs $\$ 150,000$, has a two year useful life, and produces cash flows of $\$ 24,000$ in year one and $\$ 174,000$ in year two. Investment $B$ also costs $\$ 150,000$, also has a two year useful life, but produces 
cash flows of $\$ 150,000$ and $\$ 36,000$ in years one and two, respectively. Let the firm's cost of capital be 8 percent.

In this section, consider the two investments to be independent. In other words, the decision to accept or reject asset $A$ does not impact upon the subsequent decision to accept or reject asset $B$.

\subsection{Net Present Value Analysis}

The NPV is calculated as the sum of the present values of the cash flows discounted at the cost of capital minus the cost of the investment. For investment $A$, the sum of the present values of the cash flows is $\$ 171,399.18$. Asset A requires an initial investment of $\$ 150,000$, therefore, the Net Present Value of asset $A$ is $\$ 21,399.18$. Since the NPV is positive, the firm should accept asset $A$.

Discounting the cash flows of asset $B$ at an 8 percent cost of capital produces a present value of $\$ 169,753.09$. Since asset $B$ also costs $\$ 150,000$, the NPV for asset $B$ is $\$ 19,753.09--$ a positive NPV so asset $B$ should also be accepted. As independent investments, both assets are desired according to the Net Present Value technique for capital budgeting analysis.

Columns 6 and 7 in Table 1 give the accept/reject decisions under the NPV approach to capital budgeting for various costs of capital. Asset $A$ would be acceptable over the range of discount rates for which it provides for a positive increase in wealth (discount rates up to 16 percent - column 2). Asset B increases present wealth for discount rates up to 20 percent (column 3 ) so it would be acceptable over that range.

\subsection{Internal Rate of Return Analysis}

Whereas the NPV approach examines the change in present wealth associated with accepting an investment, the IRR approach compares the expected rate of return when investing at the current price with the cost of capital for the corresponding funds. For asset $A$ and asset $B$, the IRR's are 16 percent and 20 percent, respectively. Given that both investments produce a rate of return in excess of the 8 percent cost of funds, both projects should be accepted according to the Internal Rate of Return technique.

Columns 8 and 9 of Table 1 give the accept/reject decision under the IRR approach. Comparing columns 6 and 8 indicates that the accept/reject decision is identical for Asset $A$ at the same cost of capital, regardless of whether the NPV or the IRR is used. Columns 7 and 9 confirm this conclusion for asset $B$. Therefore, for assets that are independent, the decision to accept or reject is consistent across both of the generally accepted capital budgeting techniques.

\section{Mutually Exclusive Investments}

Under the assumption of asset independence, both assets would be accepted regardless of the technique employed for the 


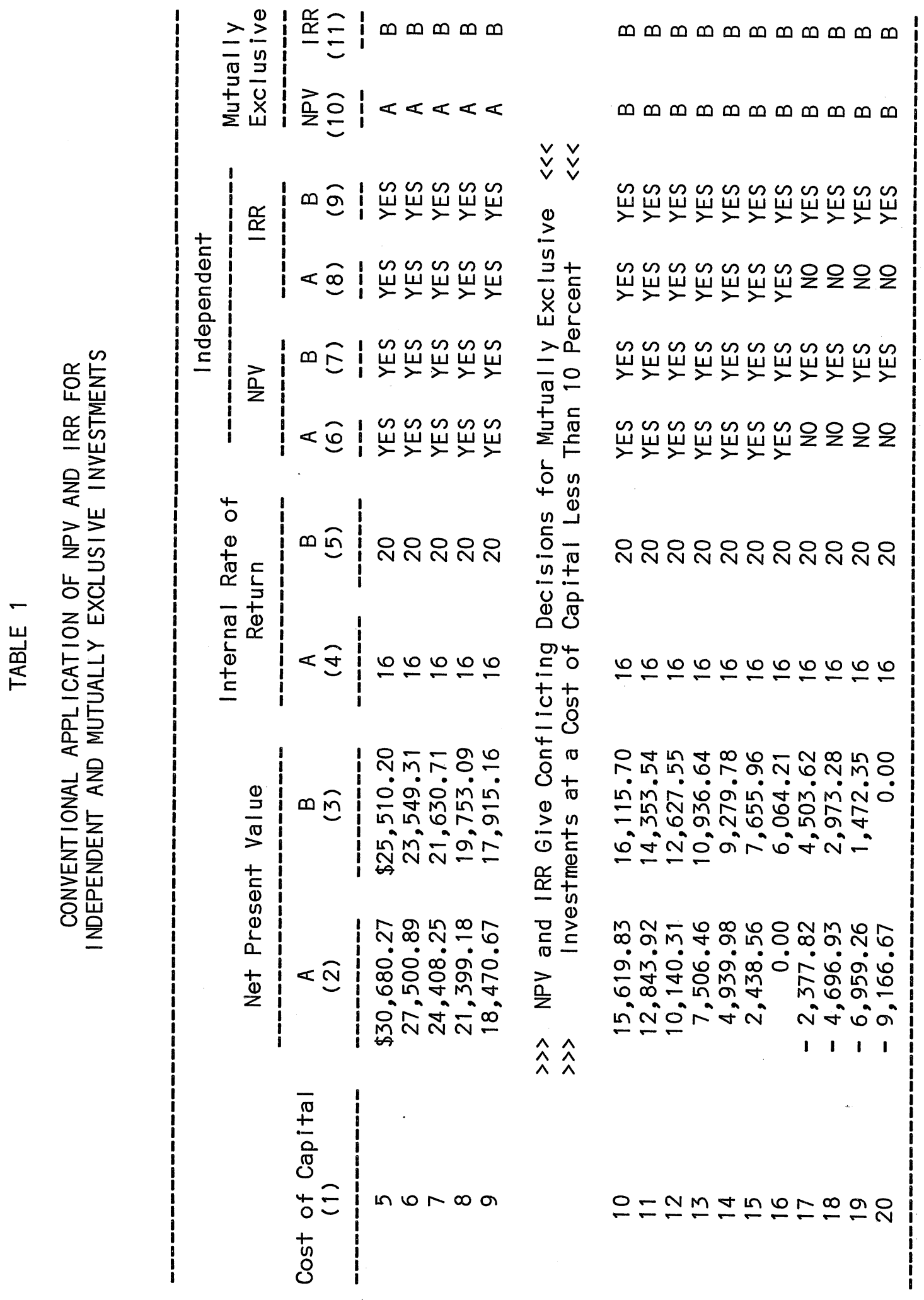


analysis. The conflict between the two techniques occurs when the assets are found to be mutually exclusive [Bacon, 1977; Doenges, 1972; Dudley, 1972].

When two assets are mutually exclusive, the decision to accept one asset precludes the acceptance of the other asset. An example of mutually exclusive investments would be if asset $A$ is an apartment building to be constructed on a particular plot of land and asset $B$ is a drive-in movie theatre for that same plot of land. Obviously, the two investments could not coexist on the same plot of land. Given that asset $A$ and asset $B$ are desirable investments, the question becomes "Which asset would be the best use of the available resources given that the firm could undertake only one of the investments?"

\subsection{Net Present Value Analysis}

According to the Net Present Value, asset A should be accepted since it increases present wealth by $\$ 21,399.18$ whereas asset $B$ only increases wealth by $\$ 19,753.09$, both at a cost of capital of 8 percent. Column 10 in Table 1 indicates the asset that increases wealth the most for the range of cost of capital. Asset $A$ should be accepted for rates through 9 percent, and asset $B$ should be accepted for rates of 10 percent or more. Although not on the table, neither asset should be accepted for rates above 20 percent. These decisions can be confirmed by comparing the Net Present Values for the two assets in columns 2 and 3 the NPV of asset A exceeds the NPV of asset B for rates through 9 percent, the opposite occurs for rates of 10 percent or more.

\subsection{Internal Rate of Return Analysis}

At a discount rate of 8 percent, the Internal Rate of Return approach would support asset $B$ since the $\$ 150,000$ is invested at a rate of return of 20 percent compounded annually versus 16 percent compounded annually for asset A. As a matter of fact, the IRR approach would support asset $B$ over asset $A$ for all discount rates less than or equal to 20 percent.

The two techniques are consistent for a cost of capital of 10 percent or more (compare columns 10 and 11). However, for discount rates less than or equal to 9 percent, the decision as to which asset is "best" depends upon the approach used in the analysis. The next section highlights the source of this conflict and demonstrates a procedure to eliminate the conflict.

\section{Reinvestment Rate Assumption}

The source of the conflict between the two capital budgeting approaches can be determined by examining the implicit reinvestment rate assumption for the two techniques. The Net Present Value analysis assumes that the $\$ 24,000$ received after the first year is reinvested by the firm at a rate of return equal to the firm's cost of capital ( 8 percent). For example, this investment has a present value of $171,399.18$ which, when invested at a rate of $8 \%$, will be worth $\$ 199,920$ at the end of the second year. The 
cash flow from the first year of $\$ 24,000$ reinvested at a rate of 8 percent and added to the second cash flow of $\$ 174,000$ will also be worth $\$ 199,920$ at the end of the second year. This illustrates that the implied reinvestment rate in the Net Present Value technique is the cost of capital [Weston and Brigham, 1981]. This does not follow economic theory, however. Since the firm continues to invest up to the point where the marginal cost of capital equals the marginal rate of return on the last investment, the actual reinvestment rate would equal the average rate of return on the total investments supported by the subsequent cash flows [Meyer, 1979].

The reinvestment rate assumption under the Internal Rate of Return is that the cash flow realized from an investment can be reinvested at a rate equal to the IRR on the original project [Weston and Brigham, 1981]. This creates a serious inconsistency under the IRR approach. Assuming both projects could be accepted, the firm would realize a cash flow of $\$ 174,000$ at the end of the first year. The IRR approach assumes that the $\$ 24,000$ from asset $A$ would be reinvested at 16 percent but the $\$ 150,000$ from asset $B$ would be reinvested at 20 percent. Intuitively this does not follow. Since the cash flows would be realized at the same time, the cash flows would enter the pool of funds available for reinvestment. It would be impossible to separate them in terms of their reinvestment potential. Once again, the actual reinvestment rate for these flows would be the average rate of return on all investment made through the pool of funds [Meyer, $1979]$.

\subsection{Net Present Value with Explicit Reinvestment Rate}

Previously it has been shown that the implicit reinvestment rate assumption under the NPV approach to capital budgeting is the firm's cost of capital. It has also been discussed that the appropriate reinvestment rate would be the average rate of return on all future investments supported by the subsequent cash flows. Table 2 shows the resulting Net Present Value analysis assuming an explicit reinvestment rate of 8 percent and 10 percent. These rates were chosen because between these rates, the IRR and the NPV ceased being consistent in their analysis of mutually exclusive investments.

In panel a of Table 2 , the rate of return on all future investments is assumed to be 8 percent. In this case, the future value of the cash flows at the end of the second year from assets $A$ and $B$ would be $\$ 199,920$ and $\$ 198,000$, respectively. Discounting these values at a cost of capital of 8 and 10 percent, Table 2 demonstrates that asset $A$ is clearly superior under the NPV technique.

Panel $b$ of Table 2 shows the same analysis assuming a reinvestment rate of 10 percent. In this case, the NPV supports asset $B$ for both costs of capital. Comparing the results in Tables 1 and 2 shows that the Net Present Value is not consistent in its selection when ignoring the explict reinvestment rate. For example, at a 10 percent cost of capital, the NPV supports the selection of asset $B$ in Table 1 but the NPV supports asset $A$ 


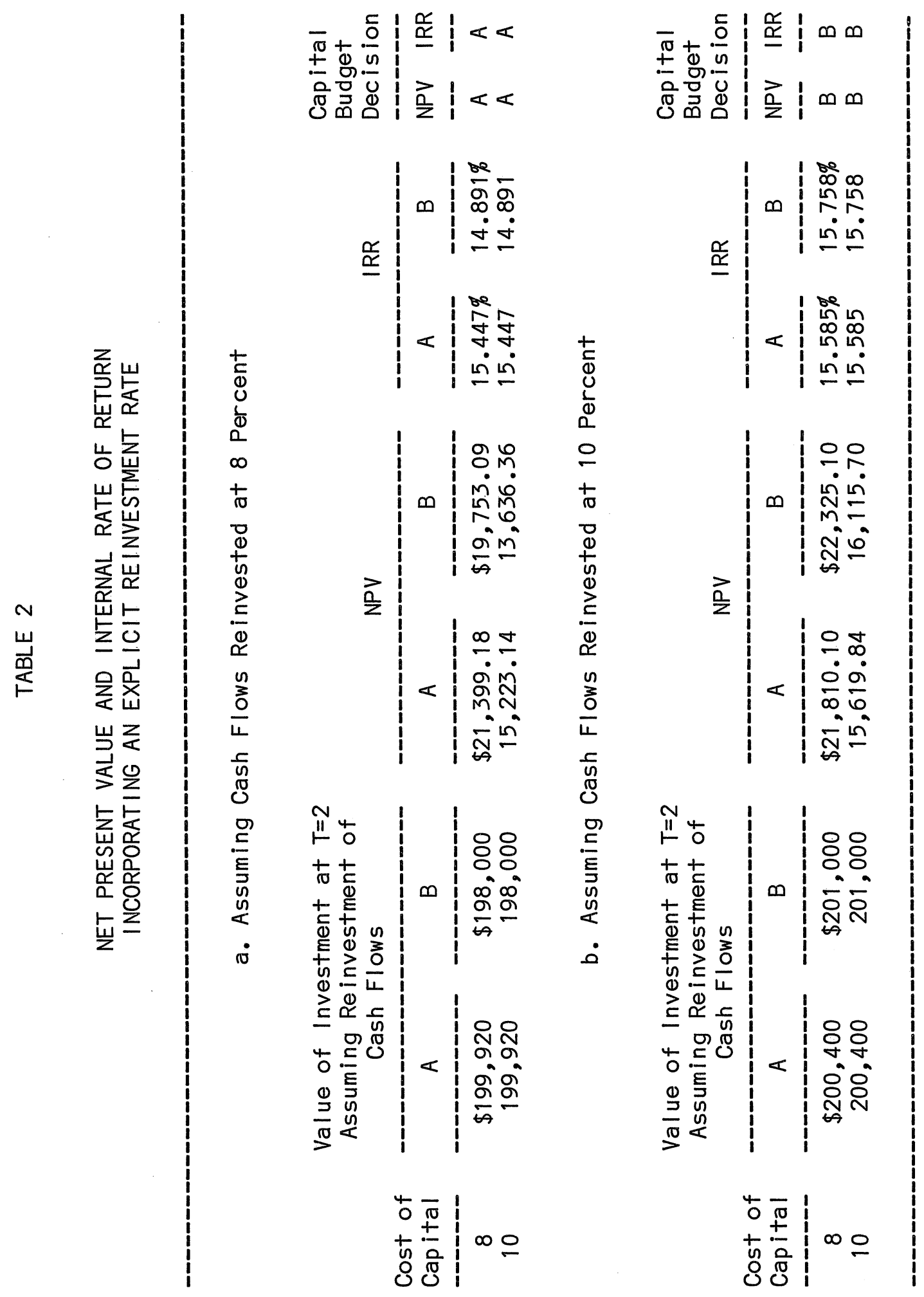


in Table 2. This illustrates the danger of applying the Net Present Value analysis without explicitly considering the reinvestment rate.

\subsection{Internal Rate of Return with Explicit Reinvestment Rate}

Panel a of Table 2 also contains the results of applying the IRR using an explicit reinvestment rate assumption of 8 percent. In this case, the IRR for asset $A$ is 15.447 percent versus 14.891 percent for asset $B$. Under the IRR, asset $A$ is considered preferred to asset $B$ for a cost of capital of 8 and 10 percent, assuming a reinvestment rate of 8 percent. These results are consistent with those from the NPV analysis, both techniques support asset $A$. Comparing these results to those is Table 1 indicates that the decision as to which mutually exclusive asset dominates changes once an explicit reinvestment rate is incorporated into the analysis -- in Table 1 the IRR supported asset $B$ for all costs of capital; whereas, in Table 2 the IRR supports asset $A$ over the same range.

When the reinvestment rate changes from 8 percent to 10 percent, the decision as to which asset to select also changes. Panel $b$ of Table 2 shows that the IRR for asset $B$ of 15.758 percent exceeds the IRR for asset $A$ of 15.585 percent so that asset $B$ should be selected. Although these results for the NPV and the IRR are consistent with those from Table 1, it cannot necessarily be generalized to all states of nature. Projects could exist whereby the conventional application of the NPV and the IRR are always incorrect. Again, correct capital budgeting decisions follow only after explicitly considering the use of the future cash flows.

\section{Summary}

The purpose of this paper is to demonstrate that the conventional applications of the Net Present value and the Internal Rate of Return techniques of capital budgeting fail when using an implicit reinvestment rate for the future cash flows. The paper also shows that the assumed superiority of the Net Present Value over the Internal Rate of Return is also incorrect. The techniques are theoretically consistent and the proper application of both will produce consistent capital budgeting decisions. The extent of the error from the conventional application of the two techniques depends upon the deviation of the explicit reinvestment rate from the implicit rate in the two approaches.

If the cash flows will be reinvested at a rate close to the firm's cost of capital, then the NPV approach will be "correct" more often than the IRR approach. Of course, if the firm is fortunate enough to reinvest at a rate that approximates the yield-to-maturity on their existing investments, the conventional application of the IRR will a produce better decision than will the NPV. In either case, to make proper capital budgeting decisions, an explicit reinvestment rate must be incorporated into the analysis whereby the selection of which technique to use for the analysis becomes a moot issue. 


\section{REFERENCES}

Bacon, Peter W. "The Evaluation of Mutually Exclusive Investments." Financial Management 6 (Summer 1977): 55-58.

Bierman, Harold, Jr., and Smidt, Seymor. The Capital Budgeting Decison: Economic Analysis of Investment Projects. New York: MacMillan Publishing Co., Inc., 1984.

Brigham, Eugene F. Fundamentals of Financial Management. New York: The Dryden Press, 1983.

Dean, Joel. "Measuring the Productivity of Capital." Harvard Business Review 32 (January-February 1954): 120-30.

Doenges, R. Conrad. "The 'Reinvestment Problem' in a Practical Perspective." Financial Management 1 (Spring 1972): 85-91.

Dudley, Carlton L., Jr. "A Note on Reinvestment Assumptions in Choosing Between Net Present Value and Internal Rate of Return." The Journal of Finance 27 (September 1972): 907-915.

Meyer, Richard I. "A Note on Capital Budgeting Techniques and the Reinvestment Rate." The Journal of Finance 34 (December 1979): $1251-54$

Weston, J. Fred, and Brigham, Eugene F. Managerial Finance. Hinsdale, Ill.: The Dryden Press, 1981. 